\title{
Nasal ventilation to facilitate weaning in patients with chronic respiratory insufficiency
}

\author{
Z F Udwadia, G K Santis, M H Steven, A K Simonds
}

\begin{abstract}
Background The non-invasive technique of nasal intermittent positive pressure ventilation (NIPPV) has an established role in providing domiciliary nocturnal ventilatory support in patients with chest wall disorders, neuromuscular disease, and chronic obstructive lung disease. NIPPV was used to simplify ventilatory management and assist the return of spontaneous breathing in patients with chronic respiratory insufficiency who had failed to wean from conventional intermittent positive pressure ventilation (IPPV).

Methods A trial of NIPPV was carried out in 22 patients with weaning difficulties. Nine patients had chest wall disorders or primary lung disease, six had neuromuscular conditions, and seven had cardiac disorders with additional pulmonary disease. Conventional IPPV via an endotracheal tube or tracheostomy had been continued postoperatively in nine patients and 13 had been ventilated after acute cardiorespiratory decompensation. Results Conventional IPPV had been continued for a median of 31 days (range 2-219). Eighteen patients were successfully transferred to NIPPV and discharged home a median of 11 days (range 8-13) after starting this type of ventilation. Sixteen patients remain well 1-50 months after hospital discharge and 10 of these continue on domiciliary nocturnal NIPPV. Seven patients have returned to work.

Conclusion NIPPV can be used to facilitate the return of spontaneous breathing and to reduce the need for intensive care accommodation in patients with an acute exacerbation of chronic respiratory insufficiency that requires intubation and IPPV.
\end{abstract}

(Thorax 1992;47:715-718)

Spontaneous ventilation is re-established uneventfully in most patients treated by mechanical positive pressure ventilation. In people with increased work of breathing or impaired ventilatory drive because of chronic cardiopulmonary disease, chest wall disorders, or neuromuscular weakness, however, stopping ventilatory support may prove difficult. Various techniques have been used to aid weaning including intermittent mandatory ventilation and inspiratory pressure support. ${ }^{1}$
Most methods require endotracheal intubation and supervision in an intensive care unit, thus causing the cost of care to escalate. In many patients a precarious balance exists between the workload and functional capacity of the resspiratory muscles, ${ }^{2}$ so that even if normal or near normal arterial blood gas tensions are maintained by day, respiratory failure may supervene at night, especially during rapid eye movement sleep.

Non-invasive nasal intermittent positive pressure ventilation (NIPPV) is an alternative to conventional intubation and positive pressure ventilation and has been used in patients with chronic and acute on chronic respiratory failure. ${ }^{3-7}$ NIPPV was used in this study to try to facilitate extubation, aid weaning, and reduce dependence on intensive care facilities in patients with severe chronic respiratory insufficiency in whom other weaning methods had failed.

\section{Patients and methods}

Twenty two consecutive patients ( 12 men and 10 women) referred with weaning difficulties were included in the study. Nine were inpatients at the Royal Brompton Hospital and 13 were transferred to this unit. Nine patients had chest wall defects or intrinsic pulmonary disease or both, six had neuromuscular disorders resulting in respiratory muscle weakness or inadequate central drive, and seven had primary cardiac disease complicated by respiratory insufficiency.

Nine patients had been treated with intermittent positive pressure ventilation (IPPV) after surgery and in the remainder acute decompensation had been precipitated by a proved or presumed respiratory tract infection or cardiorespiratory failure (see table 1). Five patients had sustained phrenic nerve injury during cardiac surgery, confirmed by diaphragm fluoroscopy and phrenic nerve conduction studies. Nine patients were being ventilated via a tracheostomy. All patients had undergone conventional weaning trials, including the use of pressure support ventilation. Each had experienced at least one attempt at extubation and some had undergone several.

Remediable causes of ventilatory insufficiency were excluded. ${ }^{8}$ The procedure of NIPPV was explained and the patient was made familiar with the nasal mask. Transfer to nasal mask ventilation was attempted if patients met the following criteria: (a) intact bulbar function with preserved cough reflex, (b) minimal airway secretions, (c) ability to breathe 
Table 1 Patient details and indications for intermittent positive pressure ventilation (IPPV)

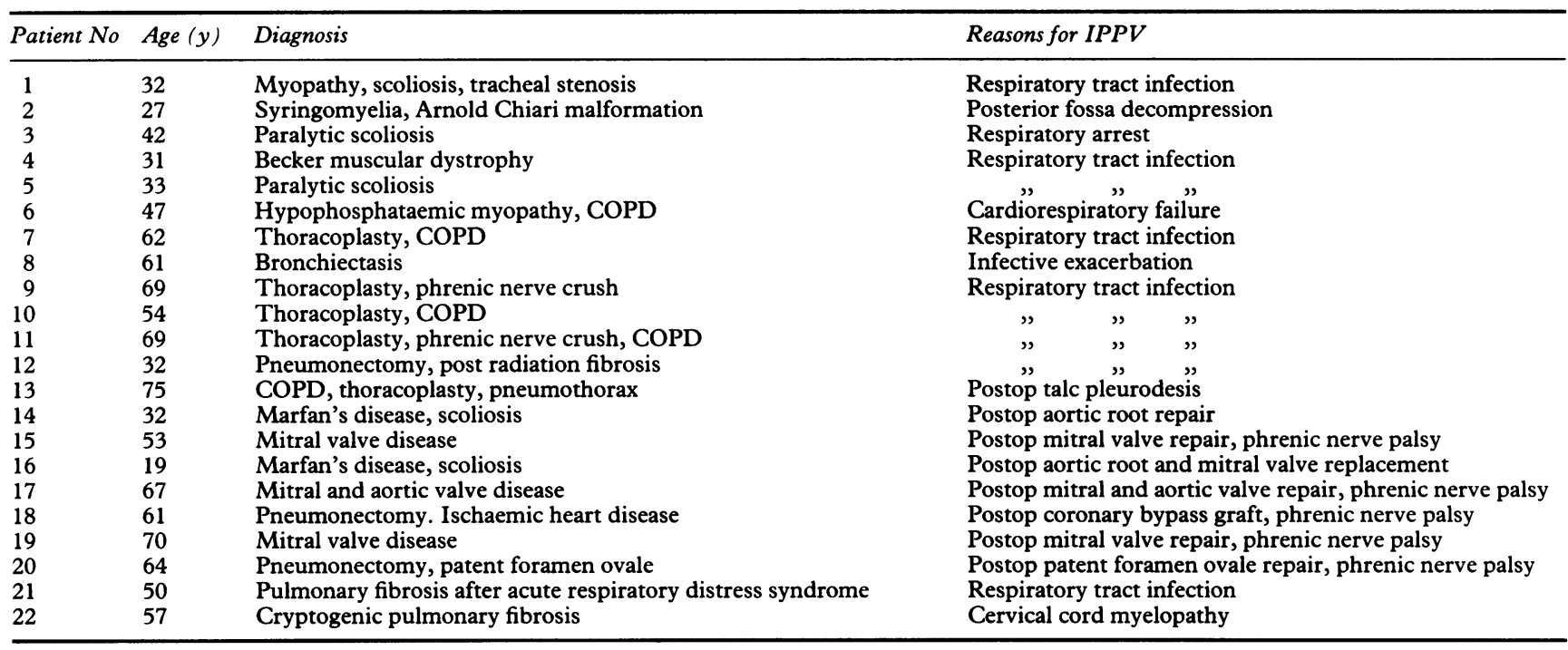

$\mathrm{COPD}=$ chronic obstructive lung disease.

spontaneously for 10-15 minutes, (d) low requirement for supplemental oxygen, (e) cardiovascular stability, and (f) functioning gastrointestinal tract.

Subjects with a nasal or oral endotracheal tube were extubated and fitted with a silicone nasal mask (Respironics Inc). In patients with a tracheostomy tube in situ, the cuff was deflated and the tube occluded. Ventilation was then begun via the nasal mask and if this was well tolerated the patient was decannulated within 24-36 hours. Volume cycled flow generator ventilators were used in 20 patients-11 BromptonPac (Pneupac Ltd), machines, five PLV-100 (Lifecare), and four Monnal D (Deva Medical). Two patients were ventilated with a BiPAP pressure support device (Respironics Inc). All ventilators were operated in the assist/ control mode. Ventilator settings were determined by arterial blood gas measurements and if supplementary oxygen was required it was added at 1-2 litres minute via the nasal mask. Humidification was not added routinely to the nasal system as normal upper airway function is preserved using this delivery route. In several patients, however, a heat and moisture exchanger (Thermovent, Portex Ltd) was placed in the circuit proximal to the expiratory valve to help decrease tenacious secretions and nasal crusting.

At first NIPPV was continued for 16-20 hours a day then it was gradually reduced to nocturnal use depending on rate of progress of the patient. On the average this took 7-14 days. The decision to stop NIPPV or discharge the patient with domiciliary equipment to use at night was based on several considerations: the diurnal arterial blood gas tensions on recovery, degree of noctural hypoventilation as assessed by overnight monitoring of arterial oxygen saturation, and transcutaneous carbon dioxide tension $\left(\mathrm{PtcO}_{2}\right)$, the natural history of the underlying cardiorespiratory disease, and the nature of the acute event that precipitated IPPV. Patients with mild to moderate nocturnal hypoventilation were treated with protriptyline 5-10 mg at night..$^{10}$

\section{Results}

The 22 patients spent a median of 31 (range 2219) days receiving conventional ventilation in an intensive care unit. Twenty of the 22 patients were successfully established on NIPPV and all of these were transferred from the intensive care unit to a general or high dependency ward within 24-48 hours. Arterial blood gas tensions during NIPPV are given in Table 2. Two subjects (patients 21 and 22), both with extensive pulmonary fibrosis, were unable to tolerate NIPPV and attempts to wean them using this method were abandoned because of dyspnoea.

After successful transfer to NIPPV, 16 patients were discharged home and two were transferred back to local hospitals and subsequently returned home. Tracheostomies were closed in all patients who were weaned from IPPV. Median hospital stay from the start of NIPPV to discharge home was 11 (range 813) days (Figure). Arterial blood gas tensions while breathing spontaneously, determined at hospital discharge, are given in table 2 . Ten patients were discharged home using nocturnal NIPPV. The remaining eight patients were discharged without mechanical ventilatory support. Four of these received treatment with protriptyline.

Two of the 20 patients who were transferred to NIPPV and were discharged from the intensive care unit required reintubation and conventional ventilation. Patient 20 experienced a pneumothorax during NIPPV and subject 19 developed intractable biventricular cardiac failure. Both patients died shortly afterwards from further medical complications.

At follow up, 1-50 (median 21) months after hospital discharge, 16 patients are well. One (patient 12) died from respiratory failure after 1 month at home having refused domiciliary ventilatory support. Patient 8 died from a lung abscess and septicaemia 6 months after discharge. Two patients were able to stop NIPPV, one after 11 and the other 24 months, and one subject was started on NIPPV 12 months after discharge because of a gradual deterioration in 
Table 2 Arterial blood gas tensions on air during nasal intermittent positive pressure ventilation (NIPPV) and before hospital discharge, spirometric data, and ventilatory status

\begin{tabular}{|c|c|c|c|c|c|c|}
\hline \multirow{3}{*}{$\begin{array}{l}\text { Patient } \\
\text { No } \\
\end{array}$} & \multirow{2}{*}{\multicolumn{2}{|c|}{$\begin{array}{l}\text { Arterial blood gases on NIPPV } \\
(\mathrm{kPa})\end{array}$}} & \multirow{2}{*}{\multicolumn{2}{|c|}{$\frac{\text { Values at discharge home }}{\text { Arterial blood gases }(\mathrm{kPa})}$}} & \multirow{2}{*}{\multicolumn{2}{|c|}{$\begin{array}{l}\text { Modes of } \\
\text { spirometry ventilation }\end{array}$}} \\
\hline & & & & & & \\
\hline & \multirow{2}{*}{$\frac{\mathrm{PaO}_{2}}{8.9}$} & \multirow{2}{*}{$\frac{\mathrm{PaCO}_{2}}{6 \cdot 0}$} & \multirow{2}{*}{$\frac{\mathrm{PaO}_{2}}{10 \cdot 2}$} & \multirow{2}{*}{$\frac{\mathrm{PaCO}_{2}}{7 \cdot 1}$} & \multicolumn{2}{|c|}{$F E V_{l} \mid F V C_{l}(m l)$} \\
\hline 1 & & & & & $1250 / 1700$ & $\mathbf{N}$ \\
\hline 2 & $11 \cdot 0$ & $5 \cdot 1$ & $10 \cdot 2$ & 6.5 & $720 / 950$ & $\mathbf{N}$ \\
\hline 3 & $9 \cdot 3$ & $7 \cdot 1$ & 8.9 & $6 \cdot 4$ & $1000 / 1100$ & $\mathbf{N}$ \\
\hline 4 & $11 \cdot 4$ & $5 \cdot 7$ & $11 \cdot 3$ & $6 \cdot 4$ & $600 / 800$ & $\mathrm{~N}$ \\
\hline 5 & $11 \cdot 1$ & 5.5 & $8 \cdot 1$ & $6 \cdot 1$ & $1200 / 1500$ & $\mathbf{N}$ \\
\hline 6 & 11.5 & 5.9 & $7 \cdot 7$ & $6 \cdot 6$ & $620 / 820$ & $\mathbf{N}$ \\
\hline 7 & 8.5 & $6 \cdot 2$ & $8 \cdot 0$ & 6.9 & $490 / 980$ & $S$ \\
\hline 8 & $9 \cdot 6$ & $5 \cdot 1$ & $7 \cdot 8$ & $7 \cdot 1$ & $550 / 825$ & $\mathbf{N}$ \\
\hline 9 & $12 \cdot 8$ & $4 \cdot 1$ & 8.4 & $5 \cdot 4$ & $540 / 710$ & $\mathrm{~s}$ \\
\hline 10 & $18 \cdot 2^{\star}$ & $5 \cdot 5$ & $8 \cdot 2$ & 6.9 & $700 / 1250$ & $\mathbf{N}$ \\
\hline 11 & 10.3 & 6.4 & $8 \cdot 2$ & 7.9 & $800 / 1400$ & $\mathbf{S}$ \\
\hline 12 & $7 \cdot 6$ & 5.4 & 8.5 & $6 \cdot 0$ & $650 / 800$ & $\mathbf{S}$ \\
\hline 13 & $10 \cdot 2$ & 6.5 & $9 \cdot 0$ & $6 \cdot 1$ & $800 / 1700$ & $S$ \\
\hline 14 & $13 \cdot 6^{\star}$ & 9.9 & $8 \cdot 4$ & 6.9 & $-/ 1200$ & $\mathrm{~N}$ \\
\hline 15 & $10 \cdot 4$ & $4 \cdot 4$ & $10 \cdot 1$ & $5 \cdot 4$ & $1400 / 1700$ & $S$ \\
\hline 16 & $13 \cdot 7$ & 5.3 & $9 \cdot 4$ & $4 \cdot 3$ & $725 / 900$ & $S$ \\
\hline 17 & 12.0 & $3 \cdot 8$ & $8 \cdot 6$ & $6 \cdot 0$ & $800 / 1250$ & $S$ \\
\hline 18 & $9 \cdot 1$ & 7.5 & $11 \cdot 1$ & $6 \cdot 7$ & -1100 & $\mathbf{N}$ \\
\hline 19 & $11 \cdot 2^{\star}$ & 7.5 & - & - & $-1-$ & D \\
\hline 20 & $11 \cdot 3^{\star}$ & $7 \cdot 1$ & - & - & -1600 & D \\
\hline 21 & - & - & - & - & $800 / 800$ & $\mathrm{~V}$ \\
\hline 22 & - & - & - & - & $-1-$ & V \\
\hline
\end{tabular}

*Arterial blood gas tensions measured while on oxygen $1 \mathrm{l} / \mathrm{min}$.

$\mathrm{N}=$ domiciliary nasal ventilation; $\mathrm{S}=$ spontaneous ventilation; $\mathrm{V}=$ continued conventional intermittent positive pressure ventilation; $\mathrm{D}=$ died.

exercise tolerance and arterial blood gas tension measurements (table 3 ). Seven of the 12 surviving patients who are below retirement age have returned to full time employment.

\section{Discussion}

Patients who cannot be weaned from IPPV place heavy demands on healthcare resources $^{11} 12$ and have a low overall survival rate. ${ }^{1314}$ NIPPV reduces the short and long term adverse effects associated with prolonged airway intubation such as infection, immobilisation, and tracheal stricture while enabling the patient to feed and communicate normally. Because NIPPV is simpler patients can be treated in a general ward thereby releasing intensive care unit beds and reducing in patient costs.

As shown here, a tracheostomy is not a

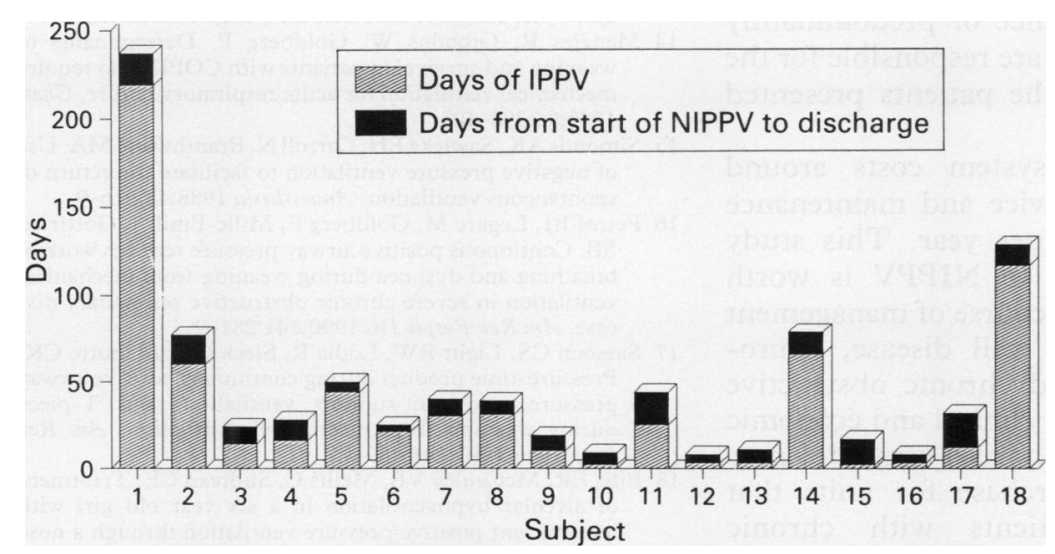

Number of days patients received conventional intermittent positive pressure ventilation (IPPV) and the number of days from the start of nasal ventilation (NIPPV) until hospital discharge. contraindication to NIPPV treatment but it is advisable to select patients with a well established tracheostomy track to reduce the risk of subcutaneous emphysema.

Other non-invasive ventilatory techniques such as negative pressure ventilation using the tank ventilator have been used to wean subjects with chronic respiratory insufficiency. ${ }^{15} \mathrm{Al}-$ though this method can be effective, negative pressure apparatus is bulky, offers a fixed rate pattern of ventilation, and predisposes patients to upper airway obstruction. Furthermore, availability of the equipment and the expertise to use it are limited. Continuous positive airway pressure (CPAP) via a nasal mask may facilitate weaning by reducing the work of breathing and the sensation of dyspnoea in patients with severe chronic obstructive pulmonary disase. ${ }^{1617}$ In this series, however, patients did not benefit from CPAP either because of the development of progressive hypercapnia or poor tolerance of the system. It seems that in some patients, particularly those with neuromuscular conditions, CPAP does not offload weak respiratory muscles adequately and cannot control severe nocturnal hypoventilation. ${ }^{18}$

The weaning methods described here have not been compared in a controlled trial in patients with chronic respiratory failure. While a controlled study would be preferable, most patients in this study acted as their own control as all conventional weaning methods had failed. Randomisation of the weaning mode in these patients seems unethical. In patients $9,10,12$, and 13-16, NIPPV was used after one unsuccessful trial of extubation to avoid the need for tracheostomy.

An obvious disadvantage of NIPPV is that it does not allow control of the airway and patients are therefore required to clear their 
Table 3 Duration of follow up and ventilatory outcome

\begin{tabular}{lll}
\hline $\begin{array}{l}\text { Patient } \\
\text { No }\end{array}$ & $\begin{array}{l}\text { Follow up } \\
(\text { mth })\end{array}$ & Ventilatory outcome \\
\hline 1 & 11 & Able to stop NIPPV at 11 months \\
2 & 44 & Nocturnal NIPPV \\
3 & 41 & Nocturnal NIPPV \\
4 & 48 & Nocturnal NIPPV \\
5 & 50 & Nocturnal NIPPV \\
6 & 27 & Protriptyline. Spontaneous ventilation until NIPPV required at 12 months \\
7 & 20 & Nocturnal NIPPV. Died at 6 months (lung abscess and septicaemia) \\
8 & 6 & Protriptyline. Spontaneous ventilation \\
9 & 13 & Nocturnal NIPPV \\
10 & 49 & Protriptyline. Spontaneous ventilation \\
11 & 1 & Protriptyline. Spontaneous ventilation. Died at 1 month (respiratory failure) \\
12 & 1 & Spontaneous ventilation \\
13 & 2 & Nocturnal NIPPV \\
14 & 2 & Spontaneous ventilation \\
15 & 20 & Spontaneous ventilation \\
16 & 9 & Spontaneous ventilation \\
17 & 12 & Able to stop NIPPV at 24 months \\
18 & 27 &
\end{tabular}

$\mathrm{NIPPV}=$ nasal intermittent positive pressure ventilation .

own secretions. Furthermore, higher minute volumes are needed compared with conventional intubation and IPPV as upper airway deadspace is included in the circuit and leaks occur from around the nasal mask and mouth, especially during sleep. ${ }^{19}$ This reduced efficiency leads to slower correction of blood gas tensions than is achieved with conventional IPPV. ${ }^{5}$

Two patients with extensive pulmonary fibrosis were unable to tolerate the pattern of ventilation generated by the nasal ventilator. The high inflation pressures and often complex ventilatory requirements of this group make it unlikely that NIPPV will be helpful in patients with widespread lung fibrosis. One subject suffered a pneumothorax. This is a potential complication of all forms of positive pressure ventilation and underlines the point that care should be taken to avoid high inflation pressures, especially when volume cycled apparatus is used.

Functional recovery has been good, as indicated by the fact that all 16 surviving patients remain at home and a proportion have returned to full time employment. Recent work has shown that ventilatory support during sleep improves arterial blood gas tensions and quality of life and reduces long term healthcare demands in patients with chronic respiratory insufficiency. ${ }^{20} \mathrm{It}$ is likely that this intervention coupled with the presence of predominantly non-progressive disease are responsible for the improved outcome of the patients presented here.

A nasal ventilator system costs around $£ 3000-£ 3500$, with service and maintenance costs of around $£ 300$ per year. This study indicates that weaning to NIPPV is worth considering early in the course of management of patients with chest wall disease, neuromuscular disorders, and chronic obstructive pulmonary disease. The clinical and economic advantages suggest that a nasal ventilator may be a cost effective purchase for units that regularly manage patients with chronic cardiorespiratory disease. Thoracic medical teams are well placed to provide a non-invasive ventilatory service and the use of NIPPV should enable thoracic physicians to play a greater part in the management of patients with chronic respiratory insufficiency who have become dependent on a ventilator.

We are grateful to Drs T Evans, B Keogh, and C Morgan for referring patients, and the staff of the high dependency and intensive care units of the Royal Brompton Hospital for patient care.

1 Tobin MJ. Weaning from mechanical ventilation. In: Simmons DH, ed. Current Pulmonary. Chicago: Year Book Publishers, 1990:47-105.

2 Goldstone J, Moxham J. Weaning from mechanical ventilation. Thorax 1991;46:56-62.

3 Kerby GR, Mayer LS, Pingleton SK. Nocturnal positive pressure ventilation by nasal mask. Am Rev Resp Dis 1987, 135:738-40.

4 Carroll N, Branthwaite MA. Control of nocturnal hypoventilation by nasal intermittent positive pressure ventilation. Thorax 1988;43:349-53.

5 Elliott MW, Steven MH, Phillips GD, Branthwaite MA. Non-invasive mechanical ventilation for acute respiratory failure. $B M J$ 1990;300:358-60.

6 Marino W. Intermittent volume cycled mechanical ventilation via nasal mask in patients with respiratory failure due to COPD. Chest 1991;99:681-4.

7 Brochard L, Isabey D, Piquet J, Amaro P, Mancebo J, Messadi AA et al. Reversal of acute exacerbations of chronic obstructive lung disease by inspiratory assistance with a facemask. N Engl J Med 1990;232:1523-30.

8 Branthwaite MA. Getting a patient off the ventilator. $\mathrm{Br} J \mathrm{Dis}$ Chest 1988;82:16-22.

9 Simonds AK, Parker RA, Branthwaite MA. The effects of protriptyline on sleep related disturbances of breathing in restrictive chest wall disease. Thorax 1986;41:586-90.

10 Caroll N, Parker RA, Branthwaite MA. Effects of protriptyline on respiratory failure in patients with chronic airflow limitation. Eur Respir J 1990;3:746-51.

11 Rosen RL, Bone RC. Economics of mechanical ventilation Clin Chest Med 1988;9:163-9.

12 Spivak D. The high cost of acute healthcare: a review of escalating costs and limitations of such exposure in intensive care units. Am Rev Resp Dis 1987;136:1007-11

13 Searle JF. The outcome of mechanical ventilation: report of a five year study. Ann R Coll Surg Engl 1985;67:187-9.

14 Menzies R, Gibbons W, Goldberg P. Determinants of weaning and survival in patients with COPD who require mechanical ventilation for acute respiratory failure. Chest 1989;95:398-405.

15 Simonds AK, Sawicka EH, Carroll N, Branthwaite MA. Use of negative pressure ventilation to facilitate the return of spontaneous ventilation. Anaesthesia 1988;43:216-9.

16 Petrof BJ, Legare M, Goldberg P, Milic-Emili J, Gottfried SB. Continuous positive airway pressure reduces work of breathing and dyspnea during weaning from mechanical ventilation in severe chronic obstructive pulmonary disease. Am Rev Respir Dis 1990;141:281-9.

17 Sassoon CS, Light RW, Lodia R, Sieck GC, Mahutte CK Pressure-time product during continuous positive airway pressure, pressure support ventilation, and T-piece during weaning from mechanical ventilation. $A m R e v$ Respir Dis 1991;143:469-75.

18 Ellis ER, McCauley VB, Mellis C, Sullivan CE. Treatment of alveolar hypoventilation in a six year old girl with intermittent positive pressure ventilation through a nose mask. Am Rev Respir Dis 1987;136:188-91.

19 Branthwaite MA. Non-invasive and domiciliary ventilation: positive pressure techniques. Thorax 1991;46:208-12.

20 Leger P, Jennequin J, Gerard M, Lassonnery S, Robert D. Home positive pressure ventilation via nasal mask for patients with neuromusculoskeletal disorders. Eur Respir $J$ 1989;2(suppl 7):640S-645S. 